Fragment di stributi on of ther mal decomposition for PS and PET wi th QMD cal cul at i ons by consi dering the excited and charged model mol ecul es

\begin{tabular}{|c|c|}
\hline 著者 & $\begin{array}{l}\text { Endo Kazunaka, Nat suntt o Chi e, Nat sumbt o } \\
\text { Dai suke, I da Tomønori, M zuno Not ohi ro, Kat o } \\
\text { Nobuhi ko }\end{array}$ \\
\hline 著者別表示 & 遠藤 一央, 井田 朋智, 水野 元博 \\
\hline $\begin{array}{l}\text { j our nal or } \\
\text { publ i cat i on title }\end{array}$ & Appl i ed Surf ace Sci ence \\
\hline vol une & 255 \\
\hline number & 4 \\
\hline page $r$ ange & $856-859$ \\
\hline year & $2008-12-15$ \\
\hline URL & ht t p: //doi . or g/10. 24517/00011058 \\
\hline
\end{tabular}




\title{
Fragment Distribution of Thermal Decomposition for PS and PET with QMD Calculations by Considering the Excited and Charged Model Molecules
}

\author{
Kazunaka Endo, Chie Masumoto, Daisuke Matsumoto, Tomonori Ida, Motohiro Mizuno, Nobuhiko Kato ${ }^{\mathrm{b}}$ \\ Department of Chemistry (Faculty of Science), Graduate School of Natural Science and Technology, \\ Kanazawa University, Kanazawa 920-1192, Japan \\ ${ }^{\mathrm{b}}$ Applied Physics, Seikei University, Musashino-city, Tokyo 180-8633, Japan \\ (*corresponding: endo@wriron1.s.kanazawa-u.ac.jp)
}

\begin{abstract}
Simulations by a quantum molecular dynamics (QMD) (MD with MO) method were demonstrated on the thermal decomposition of PS and PET polymers using the model molecules at the ground state including excited and positive charged states. For the excited and positive charged model molecules, we adopted $\mathrm{CH}_{3} \mathrm{CHC}_{6} \mathrm{H}_{5} \mathrm{CH}_{3}$ and $\mathrm{CH}_{3} \mathrm{OCOC}_{6} \mathrm{H}_{4} \mathrm{COOCH}_{3}$ of PS and PET monomers, respectively at the singlet and triplet states in single excitation, and at $(+2)$ positive charged state by semiempirical AM1 MO method. Geometry and energy optimized results of the excited and positive charged models by MO calculations were used as the initial MD step of QMD calculations. In the QMD calculations, we controlled the total energy of the system using Nóse-Hoover thermostats in the total energy range of $0.69 \sim 0.95 \mathrm{eV}$, and the sampling position data with a time step of 0.5 fs were carried out up to 5000 steps at 60 different initial conditions. The calculated neutral, positive and negative charged fragment distributions of PS and PET models with $0.82 \mathrm{eV}$ energy control were obtained as (93.5, 2.3 , and $4.3 \%)$, and $(87.8,5.3$, and $6.9 \%)$ to the total fragments, respectively. The ratios seem to correspond well to the values observed experimentally in SIMS.
\end{abstract}

Keywords: thermal decomposition; PS and PET; MD simulation; SIMS

\section{Introduction}

Standard MD has been used powerful tools to study a wide variety of events to obtain quantities that can be directly compared with experimental results as well as yield microscopic pictures about the mechanisms and reaction pathways. Some of the advanced MD method with empirical force fields ${ }^{1-5}$ has been quite successful in providing quantitative agreement with high-energy particle bombardment of organic film adsorbed on a metal substrate, ${ }^{6-9}$ and the bombardment of a polyethylene crystal. ${ }^{10}$ On the other hand, the MD approach with reactive force fields ${ }^{11-15}$ developed to simulate chemical reactions in large atomic and molecular systems, and to model thermally-induced chemical transformations in large molecules in condensed phases ${ }^{16-20}$ and thermal decomposition reactions in polymers. $^{21,22}$ However, we think the quantum molecular dynamics (QMD) method to solve the motion equations automatically without using the empirical process of the thermal decomposed reaction for polymers can be seen, and fragment distribution due to the electric charged analysis can be obtained from SCF calculations of MO method for the data at the final step of MD calculations.

*Corresponding author.

Tel.: +8176-264-5924 fax: +8176-264-5742

E-mail address:endo@wriron1.s.kanazawa-u.ac.jp
Simulation of the thermal decomposition for polymers at the ground state has already been demonstrated by a QMD method (MD with a semiempirical AM1 method). ${ }^{23}$ In the present work, we simulate the thermal decomposition of the PS and PET polymers including the excited and positive charged model molecules, because experimentalists identify some specific fragments which correspond to the excited, or charged molecular species.

\section{Computational methods}

(a) Model molecules at excited and positive charged states

For the excited and positive charged model molecules, we calculated $\mathrm{CH}_{3} \mathrm{CHC}_{6} \mathrm{H}_{5} \mathrm{CH}_{3}$ and $\mathrm{CH}_{3} \mathrm{OCOC}_{6} \mathrm{H}_{4} \mathrm{COOCH}_{3}$ of PS and PET monomers, respectively at the singlet and triplet states in single excitation, and at $(+2)$ positive charged state by the semiempirical AM1 MO method. ${ }^{24}$

Table 1 indicates C-C bond lengths of PET monomer at ground, singlet, triplet excited state and (+2) charged states, and Fig. 1 shows molecular structures of HOMO, and LUMO for PET monomer. Similar results were obtained for PS monomer, although we omit such a table and figure for PS. It can be seen from the table and figure that the length of $\mathrm{C} 3-\mathrm{C} 4$ and $\mathrm{C6}-\mathrm{C} 1$ bonds in the benzene ring at 
(+2) charged state becomes $1.51 \AA$ in the single-bond length of all states in Table $1, \mathrm{MO}$ structures of the highest occupied (HO) MO and lowest unoccupied (LU) MO at (+2) charged state is very different in comparison with that of all other states in Fig. 1. Then, we consider how the $(+2)$ charged molecule affects some specific MS fragments, since the two bond lengths (1.51 $\AA$ ) of benzene ring in $(+2)$ charged molecule are longer than normal values $(1.40 \AA)$ at ground, singlet, and triplet excited states.

Table 1. Bond lengths $(\AA)$ of PET monomer at ground, excited and charged states

\begin{tabular}{|c|c|c|c|c|c|}
\hline Structure of PET monomer & bond & Ground state & Singlet state & Triplet state & +2charged state \\
\hline${ }_{18} \varlimsup_{13}$ & $\begin{array}{l}\mathrm{C} 1-\mathrm{C} 2 \\
\mathrm{C} 2-\mathrm{C} 3 \\
\mathrm{C} 3-\mathrm{C} 4 \\
\mathrm{C} 4-\mathrm{C} 5 \\
\mathrm{C} 5-\mathrm{C} 6 \\
\text { C6-C1 } \\
\text { C6-C7 }\end{array}$ & $\begin{array}{l}1.39 \\
1.40 \\
1.41 \\
1.39 \\
1.40 \\
1.41 \\
1.48\end{array}$ & $\begin{array}{l}1.41 \\
1.41 \\
1.43 \\
1.41 \\
1.41 \\
1.43 \\
1.47\end{array}$ & $\begin{array}{l}1.43 \\
1.42 \\
1.41 \\
1.43 \\
1.41 \\
1.40 \\
1.46\end{array}$ & $\begin{array}{l}1.39 \\
1.38 \\
1.51 \\
1.39 \\
1.38 \\
1.51 \\
1.51\end{array}$ \\
\hline
\end{tabular}

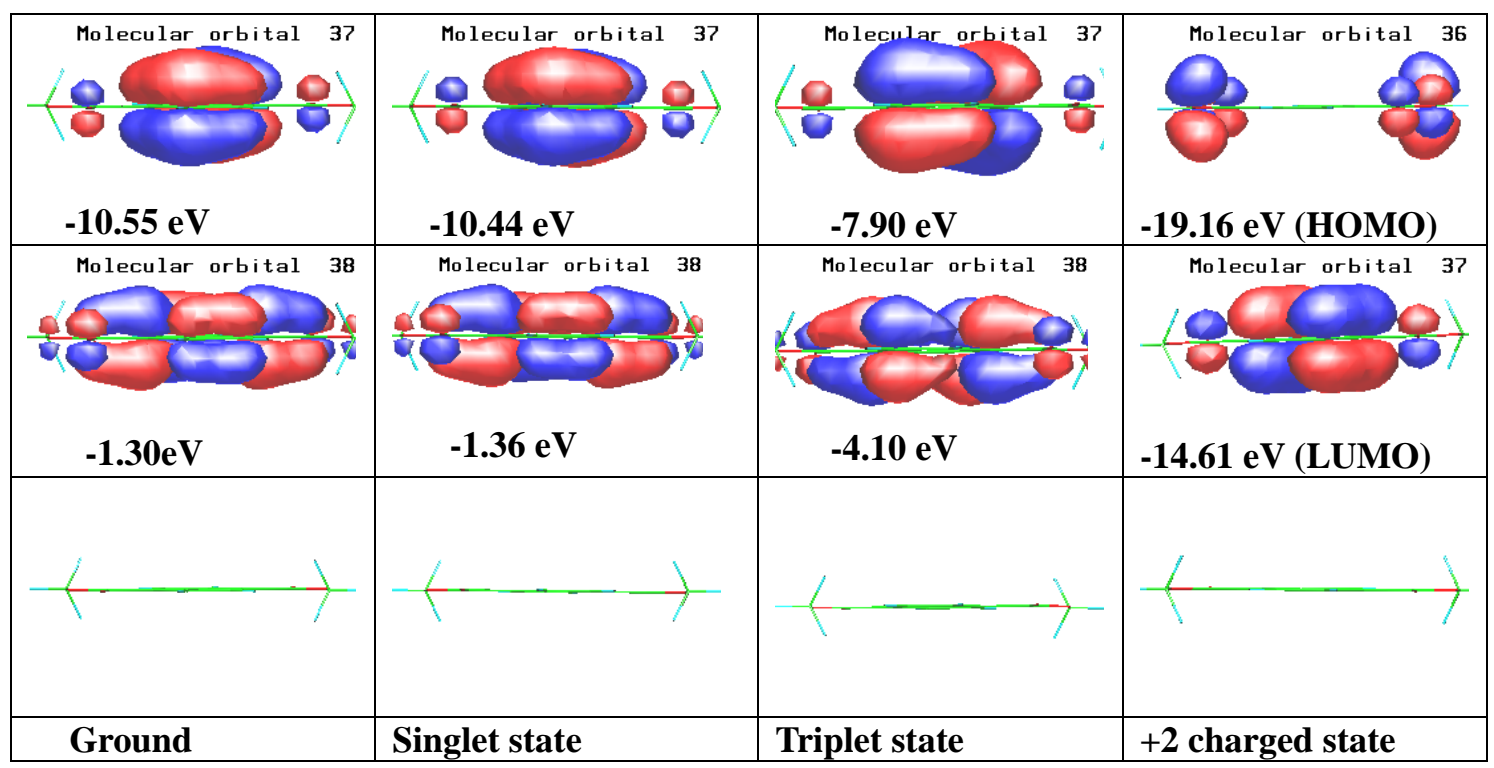

Fig. 1. MO Structures for PET monomer at ground, excited and charged states

\section{(b) QMD calculations}

The thermal decomposition of PS and PET polymers at the ground state has been simulated using the model molecules $\left[\mathrm{H}-\left(\mathrm{CH}_{2} \mathrm{CH}-\left(\mathrm{C}_{6} \mathrm{H}_{5}\right)\right)_{6}{ }^{-}\right.$ $\mathrm{H}\}$, and $\left[\mathrm{H}-\left\{\mathrm{CH}_{2} \mathrm{CH}_{2}-\mathrm{O}(\mathrm{CO})-\left(\mathrm{C}_{6} \mathrm{H}_{4}\right)-(\mathrm{CO}) \mathrm{O}\right\}_{4}-\mathrm{H}\right]$ by QMD with semiempirical AM1 MO method. Geometry and energy optimized results of the excited and positive charged model for $\mathrm{CH}_{3} \mathrm{CHC}_{6} \mathrm{H}_{5} \mathrm{CH}_{3}$ and $\mathrm{CH}_{3} \mathrm{OCOC}_{6} \mathrm{H}_{4} \mathrm{COOCH}_{3}$ of PS and $\mathrm{PET}$, respectively by $\mathrm{MO}$ calculations were used as the initial MD step in QMD calculations. The thermal energy was controlled with the Nóse-Hoover thermostats ${ }^{25,26}$ and sampling position data carried out up to 2.5 ps (5000 steps). The equations of nuclear motions were integrated using the 5 -values Gear method ${ }^{27}$ as a predictor-corrector algorithm ${ }^{28}$ with a time step of 0.5 fs.

We can obtain the distribution of thermal decomposed fragment products with positive, neutral and negative charges to the main chain carbon numbers, or the atomic mass unit from the output data of 5000 steps due to the changes of 60 random initial states for the motion of nuclear particles. Thus, the calculated distribution of the decomposition products to the number of main chain carbon atoms may be compared with the experimental results due to thermal decomposition gas mass spectrometry. On the other hand, we are able to compare the calculated positive- or negative-ion fragment spectra of the polymer model molecules with the experimental ion mass spectra in static SIMS, or time-of-flight (TOF)-SIMS.

\section{Results and Discussions}

a) Thermal decomposed process

We simulated the thermal decomposition process of PS and PET polymers using the model molecules at the ground state, and including excited and 
charged states by QMD program. As an example of data for the polymers, Fig. 2 shows the thermal decomposed data of PET model tetramer at initial, 2000, and 4000 steps with $0.82 \mathrm{eV}$ thermal energy control. It can be seen from the figure that the smaller fragments exist with the increasing sampling data steps.

For the polymers, we obtained the distribution of thermal decomposed fragment products with positive, neutral and negative charges to the main chain carbon number from the output data of 5000 steps due to the changes of 60 random initial states for the motion of nuclear particles. Thus, the calculated distribution of the decomposition products to the carbon numbers enables us to make comparisons with the experimental results due to thermal decomposed gas mass spectrometry.

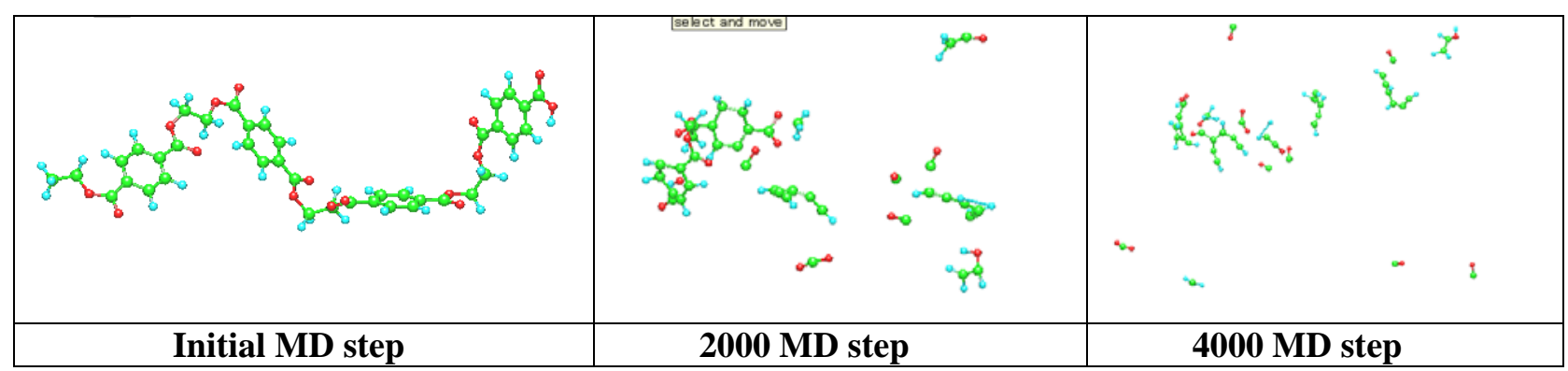

Fig.2. Thermal decomposed MD steps of PET tetramers at $0.82 \mathrm{eV}$

\section{b) Secondary positive ion fragment spectra}

In simplified emission process of a fragment ion from a solid polymer surface, an impact cascade and excited area are created around the point of primary particle impact through energy and momentum transfer from the bombarding particle to the solid polymer, when a polymer sample is bombarded by a source of ions of a few ten of $\mathrm{keV}$ of kinetic energy. The surface fragment ions are then formed by dissociation of sputtered neutral molecular species on the outer most surface layer. The surface fragment ions are thus emitted, if a sufficient amount of energy is transferred. Here we can consider that the results of the dissociation polymers correspond to the thermal decomposition in mass spectrometry. By considering the thermal decomposition, we are able to simulate the thermal decomposition of PS, and PET polymer molecules as examples by QMD method in order to compare the decomposed data at 5000 MD step in 60 runs with the experimental results in SIMS.

For the PS and PET polymers, we obtained the distribution of thermal decomposed fragments with neutral, positive, and negative charges to the atomic mass unit from the output data of 5000 step in the 60 runs. The calculated neutral, positive and negative charged fragment distributions of PS and PET models including monomer model at $(+2)$ charged state ( $5 \%$ contribution to total fragments) with $0.82 \mathrm{eV}$ energy control were obtained as (93.5, 2.3 , and $4.3 \%$ ), and (87.8, 5.3, and $6.9 \%$ ) to the total fragments, respectively. Fig. 3 shows the calculated distribution of the positive ion charged fragments for PS and PET at ground state and including $(+2)$ charged state with the experimental results of PS and PET polymers in static SIMS.$^{29}$ In

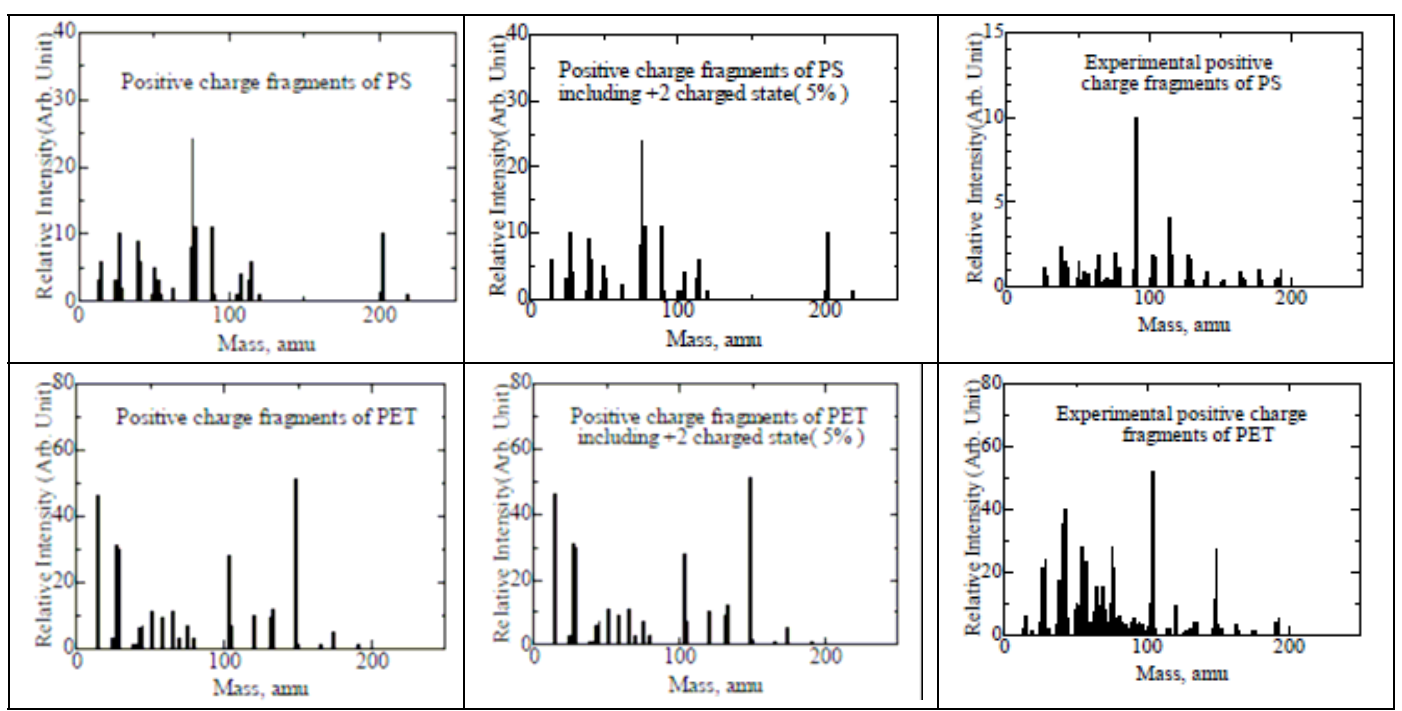

Fig. 3. Calculated distribution of the positive ion charged fragments for PS and PET with the experimental results. 
the figure, the fragment distribution for PS and PET models including $(+2)$ charged state shows similar to the results at the ground state, although we found that neutral charge fragments of carbon-5- and 7-member rings at $(+2)$ charged states occur with high probabilities in comparison with ones at the ground state. Especially for PET model, we obtained $\mathrm{C}_{7} \mathrm{H}_{4} \mathrm{O}^{+}$(104 amu) and $\mathrm{C}_{8} \mathrm{H}_{5} \mathrm{O}_{3}{ }^{+}$(149 amu) fragments which correspond well to the experimental ones.

\section{Conclusion}

A quantum molecular dynamics (QMD) (MD with semiempirical AM1 MO) method were demonstrated on the thermal decomposition process of PS and PET polymers using the hexamer and tetramer models at the ground state including both monomers $\mathrm{CH}_{3} \mathrm{CHC}_{6} \mathrm{H}_{5} \mathrm{CH}_{3}$ and $\mathrm{CH}_{3} \mathrm{OCO}-$ $\mathrm{C}_{6} \mathrm{H}_{4} \mathrm{COOCH}_{3}$, respectively at the singlet and triplet states in single excitation, and at $(+2)$ positive charged state. In the QMD calculations, we controlled the total energy of the system using Nóse-Hoover thermostats in the total energy range of $0.69 \sim 0.95 \mathrm{eV}$, and the sampling position data with a time step of 0.5 fs were carried out up to 5000 steps at 60 different initial conditions. Then, we obtained the following points:

(1) The distribution of thermal decomposed fragments of PS and PET models were given as (93.5, 2.3, and 4.3\%), and (87.8, 5.3, and 6.9\%) for the neutral, positive, and negative charges to the atomic mass unit, respectively from the output data of 5000 step in the 60 runs with 0.82 eV energy control.

(2) Ratios of the calculated fragment distribution correspond well to the values observed experimentally in SIMS.

(3) The simulated positive fragment distribution for PS and PET models including $(+2)$ charged state showed good agreement with the experimental one.

Thus, this QMD simulation enables us to use to analyze polymers in SIMS after a few ten of $\mathrm{keV}$ of primary heavy metal ion bombardment, since cleavage of polymer bonds on the outer most surface is considered as examples due to thermal decomposition process.

\section{References}

1. M. S. Stave, D. E. Sanders, T. J. Raeker, A. E. DePristo, J. Chem. Phys. 93,4413(1990).

2. T. J. Raeker, A. E. DePristo, Int. Rev. Phys.Chem. 10,1(1991).

3. C.L. Kelchner, D. M. Halstead, L. S. Perkins, N. M. Wallace, A. E. DePristo, Surf. Sci. 310,425(1994).
4. D. W. Brenner, Phys. Rev. B 42,9458(1990).

5. D. W. Brenner, J. A. Harrison, C. T. White, R. J. Colton, Thin Solid Films, 206,220(1991).

6. R. S. Taylor, B. J. Garrison, Langmuir, 11,1220 (1995).

7. K. S. S. Liu, C. W. Yong, B. J. Garrison, J. C. Vickerman, J. Phys. Chem. B 103,3195(1999).

8. R. Chatterjee, Z. Postawa, N. Winograd, B. J. Garrison, J. Phys. Chem. B 103,151(1999).

9. A. Delcorte, X. V. Eynde, P. Bertrand, J. C. Vickerman, B. J. Garrison, J. Phys. Chem. B 104,2673(2000).

10. K. Beardmore, R. Smith, Nucl. Instrum. Methods B 102,223(1995).

11. A. C. T. van Duin, S. Dasgupta, F. Lorant, W. A. Goddard,III, J. Phys. Chem., A105,9396(2001).

12. D. W. Brenner, Phys. Status Solidi B 217,23(2000).

13. A. K. Rappe, M. A. Pietsch, D. C. Wiser, J. R. Hart, L. M. Bormann-Rochotte, W. M. Skiff, Mol. Eng. 7,385(1997).

14. S. B. Sinnott, R. Andrews, D. Quan, A. M. Rao, Z. Mao, E. C. Dickey, F. Derbyshire, Chem. Phys. Lett. 315,25(1999).

15. S. J. Stuart, A. B. Tutein, J. A. Harrison, J. Chem. Phys. 112,6472(2000).

16. M. R. Nyden, in: A. F. Grand, C. A. Wilkie(Eds.), Fire Retardancy of Polymeric Materials, Marcel Dekker, New York, 2000, pp. 501-532.

17. S. I. Stoliarov, P. R. Westmoreland, M. R. Nyden, G. P. Forney, Polymer 44,883(2003).

18. M. R. Nyden, G. P. Forney, J. E. Brown, Macromolecules 25,1658(1992).

19. M. R. Nyden, T. R. Coley, S. Mumby, Polym. Eng. Sci. 37,1496(1997).

20. M. R. Nyden, in: Proceedings of the Inetrnational Aircraft Fire and Cabin Safety Research Conference, Atlantic City, NJ, 1998.

21. M. R. Nyden, S. I. Stoliarov, P. R. Westmoreland, Z. X. Guo, C. Jee, Mater. Sci. Eng. A365,114(2004).

22. K. Chenoweth, S. Cheung, A. C. T. van Duin, W. A. Goddard,III, E. M. Kober, J. Am. Chem. Soc. 127,7192(2005).

23. T. Ida, H. Sugimoto, D. Matsumoto, K. Endo, J. Surf. Anal. 12,153(2005).

24. M. J. S. Dewar, E. G. Zoebisch, Theochem 180, 1 (1988): M. J. S. Dewar, E. G. Zoebisch, E. F. Healy, J. J. P. Stewart, J. Am. Chem. Soc. 107, 3902 (1985).

25. S. Nosé, Mol. Phys.,52,255(1984): J. Mol. Phys., 81,511(1984).

26. W. G. Hoover, Phys. Rev. A31,1695(1985).

27. C. W. Gear, "The numerical integration of ordinary differential equations of various orders,” Report ANL 7126, Argonne National Laboratory(1985).

28. G. J. Martyna, M. E. Tuckerman, D. J. Tobias, M. L. Klein, Mol. Phys., 87,1117(1996).

29. J. G. Newman, B. A. Carlson, R. S. Michael, J. F. Mounlder, T.A. Hohlt, "Static SIMS Handbook of Polymer Analysis,” Perkin-Elmer Corp., Physical Electronics Division; Elden Prairie, Minnesota, 1991. 